\title{
KINERJA APARATUR PEMERINTAH DAERAH PADA UNIT PELAYANAN KESEHATAN DI KOTA PARIAMAN
}

\author{
PERFORMANCE OF LOCAL GOVERNMENT APPARATUS \\ ON HEALTH CARE UNIT IN PARIAMAN CITY
}

\author{
Imam Radianto Anwar Setia Putra \\ Pusat Peelitian Dan Pengembangan Kesatuan Bangsa, Politik Dan Otonomi Daerah \\ Badan Penelitian Dan Pengembangan Kementerian Dalam Negeri \\ Jln. Kramat Raya No. 132 Jakarta Pusat Tlp. +62 213101953 Hp. +62813 61959598 \\ e-mail: imamradianto@gmail.com \\ Diterima: 4 Januari 2012, Direvisi: 15 Februari 2012, Disetujui: 27 Februari 2012
}

\begin{abstract}
Abstrak
Pelayanan kepada masyarakat merupakan salah satu tujuan penyelenggaraan desentralisasi. Aparatur yang acuh tak acuh dalam pemberian pelayanan kepada masyarakat dan waktu pelayanan yang tidak jelas menjadi bagian dari permasalahan pemberian pelayanan. Studi ini melihat kinerja aparatur pemerintah daerah pada unit pelayanan kesehatan di Kota Pariaman. Penelitian ini mengunakan metode deskripif dengan pengukuran kinerja berdasarkan hasil akhir dan perilaku. Tuntutan debirokrasi dan peningkatan keahlian aparatur dalam pemberian pelayanan kepada masyarakat melalui pemanfaatan teknologi akan mempercepat perubahan penyelenggaraan pelayanan menjadi lebih baik.

Kata Kunci: Kinerja aparatur, penyelenggaraan pelayanan
\end{abstract}

\begin{abstract}
Public services is one of the goal of decentralization. Apparatus which is indifferent in providing services to the community and the service time that is not obviously a part of the problem of service delivery. The study looked at the performance of local government officials in health care units in the Pariaman city. This study uses a method description with performance measurement based on outcomes and behavior. de bureaucracy demands and increasing expertise in the provision of personnel services to the community through the use of technology will accelerate the implementation of service changes for the better.

Keywords: Performance of apparatus, service implementation
\end{abstract}

\section{PENDAHULUAN}

Keluhan pemberian pelayanan yang dilakukan oleh pemerintah daerah seringkali terbaca di media masa. Keluahan tersebut ditujukan terutama kepada aparatur yang bertanggung jawab mengelola pelayanan. Di sisi lain rentang pelayanan yang panjang, kualitas pelayanan yang seadanya, dan biaya yang mahal memperburuk kondisi pelayanan pemerintah daerah. Kapasitas aparatur dan organisasi menjadi sorotan yang harus dibenahi agar dapat menghasilkan penyelenggaraan pelayanan yang efektif, efisien dan ekonomis.

Penghargaan serta hukuman yang belum berjalan secara maksimal mem-bangun celah serta kebiasaan para aparatur untuk melakukan tindakan di luar prosedur yang ada. Profesionalitas aparatur dalam unit kerja pelayanan diperlakukan dan begitu juga dengan aparatur yang bekerja dijajaran struktural. Kinerja pelayanan pada masyarakat seharusnya disesuaikan dengan prosedur dan sumpah menjadi pegawai negeri sipil (PNS), sehingga tidak ada lagi embel-embel uang pelicin. Hal ini menunjukkan tidak adanya komitmen moral aparatur dan kurangnya profesionalisme aparatur setiap menjalankan tugas dalam melayani masyarakat.
Rendahnya profesionalisme aparatur pada unit pelayanan seringkali ditunjukkan dalam sebuah kasus, apabila penguna jasa menginginkan pelayanan cepat dan orang penting, etah itu saudara atau yang mereka kenal, maka pimpinan yang akan menanganinya. Ironisnya apabila pengguna jasa itu orang biasa, maka pelayanan yang diberikan cenderung berbeda.

Penyelenggaraan pelayanan publik yang dilakukan oleh pemerintah daerah masih dihadapkan pada sistem pemerintahan yang belum efektif dan efisien serta kualitas sumberdaya manusia aparatur yang belum memadai. Dukungan manajemen dalam penyelenggaraan sistem pemerintahan dan SDM aparatur sebagai mesin dalam menjalankan organisasi selalu menjadi sorotan utama dalam melaksanakan pelayanan di daerah. Lemahnya kemam-puan, wawasan, perilaku, dan mindset yang dimiliki oleh aparatur membawa dampak pada kinerja penyelenggaraan pelayanan publik.

Selama ini, salah satu faktor internal yang menganggu lingkungan unit pelayanan di daerah adalah pola pikir. Pola pikir birokrasi dan aparaturnya lebih mengedepankan prosedur sebagai alat untuk fungsi kontrol yang merupakan alat kekuasaan warisan kolonial Belanda (Dwiyanto, 
2010). Belum terbentuknya mindset sebagai pelayan bagi masyarakatnya, mulai dari tataran pimpinan/kepala unit kerja hingga para aparatur pelaksana teknis pada unit pelayanan.

Berdasarkan uraian masalah dimulai, maka dapat diidentifikasikan hal-hal sebagai berikut: kurangnya profesionalisme aparatur, ketidakpastian waktu dan biaya, kurangnya komitmen moral aparat, rendahnya disiplin aparatur, budaya dilayani bukan melayani, dan kurangnya koordinasi yang baik di dalam lingkungan unit kerja pelayanan di daerah merupakan permasalahan yang tidak kunjung usai dalam implementasi kinerja aparatur pelayanan di daerah. Berdasarkan latar belakang di atas, permasalahan dititikberatkan pada kinerja aparatur di unit kerja pelayanan. Pertanyaan utama adalah bagaimana kinerja aparatur pada unit pelayanan di daerah? Tentunya aparatur yang dimaksud dalam penelitian ini adalah PNS yang bekerja di unit kerja pelayanan kesehatan Kota Pariaman.

Definisi kinerja menurut Mangkunegera (2001), adalah hasil kerja secara kualitas dan kuantitas yang dicapai oleh seseorang aparatur dalam melaksanakan tugas yang diberikan kepadanya. Penilai tersebut berdasarkan jumlah pekerjaan yang dilaksanakan atau fungsi-fungsi yang melekat dalam unit kerja serta hasil yang dicapai sehingga dapat dimanfaatkan oleh para penggunanya (user). Selanjutnya, menurut Gomes. F, (1995) dikatakan bahwa performansi pekerjaan adalah catatan hasil atau keluaran (outcomes) yang dihasilkan dari suatu fungsi pekerjaan tertentu atau kegiatan tertentu dalam suatu periode waktu tertentu. Ringkasan yang dikeluarkan dengan menilai fungsi yang dilakukan dalam memlakukan pekerjaan sehingga memberikan masukan dalam memngabil serta mencari solusi untuk peningkatan dan hasil yang hendak dicapai untuk memenuhi tujuan organisasi. Dalam hal ini pegawai negeri sipil (PNS) juga memiliki bentukbentuk penilaian yang sesuai dengan tugas pokok dan fungsi masing-masing yang terdapat pada setiap unit kerjanya. Aparatur pelayanan dalam penelitian ini adalah (PNS) yang dijadikan pelaksana tugas dalam rangka memenuhi tuntutan pelayanan kepada masyarakat secara langsung. Penilaian terhadap PNS dituangkan dalam daftar penilaian pelaksanaan pekerjaan (DP-3), yakni suatu daftar yang memuat hasil penilaian pelaksanaan pekerjaan seorang PNS dalam jangka waktu 1 (satu) tahun yang dibuat oleh pejabat penilai yang memiliki tujuan untuk memperoleh bahan-bahan pertimbangan yang obyektif dalam pembinaan PNS dengan mengunakan beberapa unsur dalam menilai. Penilaian tersebut dilakukan kepada PNS yang bekerja di seluruh unitunit kerja penyelenggaraan pemerintah.

Banyak aspek memengaruhi kinerja seseorang. Lingkungan organisasi, motivasi kerja, gaya kepemimpinan, perilaku, sikap dan tindakan rekan sejawat menjadi faktor penentu kinerja individu. Dalam konteks kinerja ini unit pelayanan di daerah mengacu pada Prinsip Pelayanan Publik sesuai dengan Kep. Menpan No: 63/KEP/M.PAN/7/2003 tentang Pedoman Umum Penyelenggaraan Pelayanan Publik. Pada umumnya merefleksikan budaya birokrasi dengan hirarki jabatan struktural birokrasi di Indonesia. Padahal, unit pelayanan membutuhkan struktur organisasi yang mampu memberikan pelayanan cepat dan memuaskan kepada masyarakatnya sesuai dengan apa yang diharapkan. Boyne dan Walker (2005) menyatakan bahwa kinerja organisasi sektor publik umumnya terfokus pada hambatan dan stimulus yang berasal dari faktor-faktor eksternal, seperti aturan hukum dan ketidakpastian lingkungan.

Pada umumnya aparatur pelayanan belum profesional, dan menciptakan biaya tinggi dalam mendapatkan pelayanan yang dirasakan oleh kebanyakan masyarakat dan menjadikan tuntunan masyarakat untuk mendorong penyelenggaran pelayanan, yaitu pemerintah daerah untuk kembali kepada misi dan visinya sebagaimana dibentuknya daerah. Dibutuhkan seorang pelayan yang baik dalam memberikan pelayanan kepada masyarakat yang merupakan pengguna layanan, yang mampu memberikan kualitas pelayanan yang baik. (Kep Menpan nomor 63/KEP/M.PAN/ 7/2003).

Terdapat beberapa kriteria jenis pelayanan yang dapat dikategorikan sebagai pelayanan publik (Dwiyanto, 2010). Kriteria pertama, yang biasa digunakan adalah sifat dari barang dan jasa itu sendiri dan kriteria kedua yang dapat digunakan untuk pelayanan. Tidak kalah pentingnya kinerja pelayanan yang dilaksanakan oleh aparatur di daerah juga dapat dilihat dari produk yang dihasilkan dari kegiatan tersebut. Terdapat 5 (lima) dimensi (Kotler, 1991) dengan dirancang untuk mengukur kualitas pelayanan yang didasarkan pada perbedaan antara nilai harapan dengan nilai kinerja yang dirasakan oleh konsumen, yaitu: 1) Responsive (daya tanggap/ kesigapan) adalah suatu respon/kesigapan pegawai dalam membantu konsumen dan memberikan pelayanan yang cepat dan tanggap; 2) Reliability (keandalan) adalah suatu kemampuan untuk memberikan jasa yang dijanjikan dengan akurat dan terpercaya; 3) Assurance (jaminan) adalah kemampuan pegawai atas pengetahuan terhadap produk secara tepat, kualitas, keramahtamahan, perkataan atau kesopanan dalam memberikan pelayanan, keterampilan dalam memberikan informasi dan ke-mampuan dalam menanamkan kepercayaan konsumen/pelanggan terhadap perusahaan; 4) Emphaty (perhatian) adalah kemampuan perusahaan dalam memberikan perhatian yang bersifat individual atau pribadi kepada para pelanggan/konsumen; dan 5) Tangibles (kemampuan fisik) adalah suatu bentuk penampilan fisik, peralatan personal, media komunikasi, dan halhal yang lainnya yang bersifat fisik.

Selanjutnya kinerja aparatur juga dapat diukur berdasarkan perilaku lebih menekankan pada cara 
atau sarana (means) dalam mencapai tujuan dan bukan pada pencapaian hasil akhir. Pengukuran berdasarkan perilaku umumnya bersifat subjektif dimana diasumsikan pegawai dapat menguraikan dengan tepat kinerja yang efektif untuk dirinya sendiri maupun untuk rekan kerjanya serta pengukuran kinerja berdasarkan perilaku memungkinkan pengungkapan aspek-aspek pekerjaan yang lebih luas sehingga diperoleh gambaran kinerja yang komprehensif (Faustion Gomes, 1995). Tujuan penilaian kinerja adalah untuk mengetahui keberhasilan atau ketidak berhasilan seorang PNS, dan untuk mengetahui kekurangankekurangan dan kelebihan-kelebihan yang dimiliki oleh PNS yang bersangkutan dalam melaksana-kan tugasnya. Hasil penilaian kinerja digunakan sebagai bahan pertimbangan dalam pembinaan PNS, antara lain pengangkatan, kenaikan pangkat, pengangkatan dalam jabatan, pendidikan dan pelatihan, serta pemberian penghargaan.

Gomes, F. (1995) lebih lanjut menjelaskan terdapat 2 (dua) kriteria pengukuran performansi atau kinerja karyawan, yaitu 1) pengukuran berdaarkan hasil akhir (result-based performance evaluation); dan 2) pengukuran berdasarkan perilaku (behaviour-based performance evaluation). Pengukuran berdasarkan hasil akhir, mengukur kinerja berdasarkan pencapaian tujuan organisasi atau mengukur hasil-hasil akhir saja.

\section{METODE PENELITIAN}

Penelitian ini menitikberatkan pada kinerja aparatur pemerintah daerah yang berkarya di unit pelayanan kesehatan daerah. Penelitian ini menggunakan metode deskriptif untuk menjawab pertanyaan penelitian dengan memilih locus Kota Pariaman. Unit analisis dalam studi ini adalah pusat kesehatan masyarakat (puskesmas) di 7 (tujuh) kecamatan dengan metode proposive sampling. Memerhatikan keterbatasan yang dimiliki, maka dalam penelitian ini ditentukan hanya 3 (tiga) puskesmas yang terdapat di Kota Pariaman.

Dalam mengukur kinerja aparatur pada unit kerja pelayanan kesehatan diihat melalui kedua kriteria performansi kinerja, yaitu: 1) Pengukuran berdasarkan hasil akhir (result-based performance evaluation) yang dilihat dari dimensi pelayanan; dan 2) Pengukuran berdasarkan perilaku (behaviourbased performance evaluation) dilihat dari instrumen prilaku kinerja.

Jenis data yang dibutuhkan adalah data primer dan data sekunder. Data primer dikumpulkan melalui wawancara mendalam terhadap 5 (lima) informan per puskesmas. Data Sekunder diperoleh dari berbagai literatur, laporan dinas, dokumen, serta hasil penelitian yang terkait atau sejenis.

\section{Gambaran Lokasi Penelitian}

Kota Pariaman merupakan daerah otonom hasil pemekaran dari Kabupaten Padang Pariaman. Dibentuk berdasarkan Undang-undang Nomor. 12 Tahun 2002 tentang Pembentukan Kota Pariaman di Provinsi Sumatera Barat. Secara geografis Kota Pariaman terletak di pantai Barat pulau Sumatera dan berhadapan langsung dengan Samudera Indonesia. Kota Pariaman pada sisi Utara, Selatan, dan Timur berbatasan langsung dengan Kabupaten Padang Pariaman dan di sebelah Barat berbatasan dengan Samudera Indonesia.

Jumlah penduduk Kota Pariaman pada tahun 2009 sebanyak 78.802 jiwa, yang terdiri dari 38.724 jiwa laki-laki dan 40.078 jiwa perempuan. Kepadatan penduduk pada tahun 2009 adalah sebesar 1.083 jiwa per $\mathrm{Km}^{2}$. Kecamatan Pariaman Tengah adalah kecamatan dengan kepadatan penduduk tertinggi, yakni sebanyak $1.874,74$ jiwa per $\mathrm{Km}^{2}$. Puskesmas di Kota Pariaman sebanyak 4 buah dan meningkat menjadi 6 buah pada tahun 2008, sedangkan jumlah puskesmas perawatan sebanyak 1 (satu) buah. Puskesmas menganut konsep wilayah dan diharapkan dapat melayani sasaran penduduk rata-rata 30.000 penduduk. Artinya 1 (satu) puskesmas di Kota Pariaman rata-rata melayani sebanyak 20.288 jiwa. Puskesmas pembantu pada tahun 2007 berjumlah 9 buah. Rasio Puskesmas terhadap puskesmas pada tahun 2007 rata-rata 2.2:1. Artinya setiap puskesmas didukung oleh 2 sampai 3 Puskesmas Pembantu dalam memberikan pelayanan Kesehatan kepada masyarakat, selain itu dalam menjalankan tugas operasionalnya didukung oleh puskesmas keliling sejumlah 14 (empat belas) buah.

Ketersediaan tenaga kesehatan di Kota Pariaman sebesar 280 orang, tersebar di Puskesmas sebanyak 211 orang dan Dinas Kesehatan Kota Pariaman 69 orang. Dari data yang ada nampak bahwa SDM kesehatan didominasi oleh perawat bidan yang jumlahnya mencapai 155 orang, medis 22 orang, farmasi 23 orang, gizi 9 orang, teknisi medis 15 orang, sanitasi 12 orang, dan kesehatan masyarakat 23 orang. dalam melayani kesehatan seluruh penduduk Kota Pariaman pada tahun 2009 memiliki 21 orang dokter umum, 9 orang dokter gigi, 43 orang sarjana kesehatan masyarakat, 48 orang sarjana farmasi, dan 6 orang sarjana kesehatan.

Pada tahun 2009 terjadi kenaikan jumlah kunjungan pada Puskesmas Pariaman, yaitu 37.917 hanya sebesar 2009, sedangkan pada tahun 2008 adalah 28.686. Hal ini menunjukkan bahwa kepercayaan masyarakat untuk berobat ke Puskesmas telah meningkat sejalan dengan telah meningkatnya kesadaran masyarakat untuk menjaga kesehatannya dengan berobat ke Puskesmas.

\section{HASIL DAN PEMBAHASAN}

Pelayanan di Unit Kesehatan
Perilaku aparatur kesehatan dalam
memberikan pelayanan agar lebih dekat dengan


masyarakat dilakukan dengan cara melihat intensitas kedatangan masyarakat untuk mendapatkan pelayanan dan dengan lokasi yang mudah dijangkau, memadai, tempat sehingga rasa nyaman dapat diterima pengguna pelayanan. Hasil observasi dibeberapa puskesmas pengguna pelayanan sudah sangat banyak dan terlihat masih harus menyediakan tempat yang memadai untuk mendukung pekerjaan dalam pemberian pelayanan.

Kemampuan yang dimiliki oleh aparatur yang ada di beberapa puskesmas dalam berkomunikasi dan penampilan yang baik masih dirasakan sangat rendah, penyampaian serta pemberian penjelasan pelayanan kepada masyarakat yang ingin mendapatkan pelayanan. Sikap aparatur dalam memberikan pelayanan terkadang tidak memerdulikan kebutuhan dan keinginan masyarakat sebagai pengguna layanan. Sikap aparatur menjadi perhatian dalam pemberian pelayanan, setidaknya ada acuan dalam memberikan pelayanan kepada masyarakat.

Selain sikap dari aparatur juga memerhatikan perkembangan teknologi ada pada masa ini, perlu pemanfaatan teknologi yang dalam mendukung pelayanan kesehatan di beberapa unit Puskesmas Kota Pariaman. Belum seluruhnya menggunakan dan memanfaatkan teknologi yang ada. Pelayanan masih bersifat konvesional dan masih sangat sederhana dengan melihat pemahaman masyarakat. Dirasakan sementara ini penggunaan teknologi berimplikasi pada biaya yang cukup tinggi sehingga dirasa masih kurang tepat untuk saat ini.

Perasaan nyaman juga dirasakan masyarakat ketika puskesmas dapat mudah diakses dari tempat tinggal dan tersedianya fasilitas sarana transportasi. Pada Kota Pariaman jangkauan unit pelayanan kesehatan yang dirasakan oleh masyarakat relatif mudah dijangkau dan ditemui, melihat posisi dan letak puskesmas pada daerah-daerah yang mudah dijangkau dan diakses oleh masyarakat baik dari seluruh pelosok Kota Pariaman.

Selain aksesbilitas, dukungan kelengkapan sarana dan prasarana kesehatan untuk pemeriksaan kesehatan bagi masyarakat di unit pelayanan kesehatan cukup memadai. Sayangnya, tidak diikuti penyediaan sarana pendukung dan penunjang lainnya, seperti ruang tunggu dan tempat parkir yang dapat menambah rasa nyaman dalam pemberian pelayanan kesehatan kepada masyarakat. Ruang pelayanan mudah ditemui pengguna pelayanan yang berkunjung dan memanfaatkan pelayanan yang disediakan oleh beberapa puskesmas yang disediakan pemerintah Kota Pariaman.

Dukungan pemberian pelayanan kepada masyarakat yang dilakukan oleh unit pelayanan kesehatan dalam memberikan informasi kepada penggua pelayanan sudah memiliki papan informasi yang membantu menjelaskan kepada masyarakat dalam mendapatkan dan menerima pelayanan yang akan diberikan kepada masyarakat. Terdapat juga perbedaan pemberian pelayanan juga dirasakan oleh masyarakat, dengan melihat perbedaan tersebut antara masyarakat yang memiliki kemampuan menegah ke atas dengan masyarakat menegah ke bawah, dapat tidak terjadi apabila aparatur tersebut memiliki komitmen dalam memberikan pelayanan kesehatan kepada masyarakat.

Tidak kalah pentingnya, dalam pemberian pelayanan dibutuhkan keandalan, ketepatan waktu dalam memberikan pelayanan kepada masyarakat, sehingga mendorong masyarakat untuk tetap datang mendapatkan pelayanan kesehatan yang masksimal oleh aparatur pelayanan di unit pelayanan kesehatan. Dengan adanya kejelasan baik waktu dan biaya yang ditetapkan guna mendapatkan pelayanan kesehatan dengan didukung papan informasi menghasilkan kejelasan pelayanan serta tarif yang sudah tertera langsung sehingga dapat memberikan kepastian dalam mendapatkan pelayanan kepada masyarakat pengguna layanan.

Kedisipilinan aparatur fungsional yang merupakan tulang punggung pelaksana pelayanan di setiap unit pelayanan, kehadiran dokter ataupun fungsional lainnya dalam menyelenggarakan pelayanan kepada masyarakat. Hal ini sangat dirasakan oleh masyarakat pengguna pelayanan di unit pelayanan kesehatan dalam menerima pelayanan. Ketepatan waktu dalam pemberian pelayanan masih sangat rendah dan hal itu benarbenar sangat dirasakan oleh masyarakat pengguna pelayanan.

Lingkungan pada unit pelayanan harus dibangun secara bersama-sama dalam mencapai tujuan pemberian pelayanan yang baik kepada masyarakat, lingkungan organisasi unit pelayanan kesehatan memiliki orientasi yang jelas dalam pemenuhan pelayanan, terkadang kepentingan individu menjadi penghalang pemberian pelayanan, dimana ada alasan yang sangat klasik yang sering diungkapkan dalam pemberian pelayanan kepada masyarakat.

Komitmen aparatur pelayanan baik tenaga administrasi dan fungsional menitikberatkan kepada pemberian pelayanan secara optimal kepada masyarakat. Adanya peraturan yang memberikan izin kepada tenaga fungsional medis yang dapat memberikan pelayanan secara pribadi atau individual dan mandiri menjadikan pelayanan yang di berikan pada unit pelayanan kesehatan tidak maksimal dan terkesan setengah hati, pada akhirnya masyarakat sebagai pengguna menjadi korban dalam menerima pelayanan yang kurang baik.

Kemampuan aparatur dalam memberikan pelayanan yang cepat dan tepat masih jauh dari harapan, jika ditanyakan kepada dinas kesehatan tentang Standard Operating Procedure (SOP) pelayanan puskesmas sudah ditetapkan dan dimiliki setiap unit pelayanan sayang belum dirasakan oleh masyarakat secara utuh dan menyeluruh. Sehingga perlunya ada evaluasi terkait SOP terebut dan 
pelaksanaan kerja yang dilakukan guna memberikan pelayanan kesehatan kepada masyarakat. Pelayanan juga memastikan pengguna atau konsumen mendapatkan jaminan atas kepastian pelayanan yang diberikan, dengan melihat kompetensi apratur dalam memberikan pelayanan pada unit pelayanan kesehatan. diharapkan yang menjadi harapan masyarakat dalam menggunakan pelayanan tersebut dapat dipenuhi secara baik.

Kompetensi yang meliputi kemampuan, prilaku dan pengetahuan masih sangat rendah diterapkan dalam pelayanan kepada masyarakat. Kompetensi yang ada tersebut belum menjadi acuan dalam memberikan pelayanan kepada masyarakat, membuat jaminan terhadap pemberian pelayanan kesehatan yang baik di unit pelayanan tesebut masih rendah. Prilaku inovatif tidak begitu terlihat dalam pemberian pelayanan kesehatan kepada masyarakat, pelayanan kesehatan memilik tahapan-tahapan yang jelas sehingga waktu pun sudah dapat dihitung. Pekerjaan tidak memberikan ruang dalam memberikan kreatifitas pemberian pelayanan kepada masyarakat di daerah untuk itu perlu kerja yang cekatan dan teliti dalam menjadikan pekerjaan itu bisa menjadi lebih efisiena dan efektif sehingga bisa mendukung dan memberikan pelayanan yang baik kepada masyarakat. Memang masih terdapat beberapa kendala dalam mendukung pelayanan yang terdapat di kota Pariaman, tempat yang belum representatif dan nyaman yang digunakan dalam pemberian pelayanan kepada masyarakat, dimana masih terdapat beberapa ruang dan kondisi unit pelayanan kesehatan yang masih perlu penambahan sehingga nantinya mendukung pemberian pelayanan kepada masyarakat.

Komunikasi sangat terbuka di dalam unit pelayanan kesehatan pada Kota Pariaman. Kesempatan dan peluang yang sebesar-besarnya dalam membentuk iklim organisasi mendorong keterbukaan antara masing-masing aparatur yang melaksanakan tugas pada unit pelayanan kesehatan. Kesempatan untuk dapat memperoleh pelayanan yang baik juga dilakukan melalui penyampaian keluahan kepada Bapak Walikota melalui SMS (short massages services) dalam menyampaikan keluhan terhadap pelayanan yang diberikan oleh aparatur pelaksana kesehatan pada unit pelayanan kesehatan kepada pengguna pelayanan. Terkadang pelaksanaan pekerjaan yang terjadi di unit pelayanan kesehatan membuat tidak tampaknya garis pemisah antara jenjang struktural serta fungsional aparatur pelayanan kesehatan tersebut. Kondisi ini membuat pelayanan di unit pelayanan kesehatan hanya sekedarnya saja, ego antara tenaga fungsional medis dan tenaga struktural membuat kepemimpinan di unit pelayanan kesehatan menjadi lemah. Kepala unit pelayanan tidak memiliki kemampuan atau perangkat yang mendukung untuk menindak aparatur fungsional yang melakukan kesalahan dalam pemberian pelayanan, baik itu dokter atau bidan yang menerima pelayanan di klinik sendiri pada jamjam kerja Puskesmas dan berpontensial konflik antar aparatur fungsional dengan pimpinan pada unit pelayanan kesehatan.

Pelayanan yang dilakukan pada unit pelayanan kesehatan juga tentunya memiliki pesaingpesaing dari pihak non pemerintah. Seringkali pemberian pelayanan yang dilakukan di unit pelayanan kesehatan berlanjut kepada klinik independen yang dimiliki oleh aparatur kesehatan yang bekerja di unit pelayanan kesehatan tersebut. Dalam penelusuran, seperti sudah dijelaskan di atas pada akhirnya pelayanan diselesaikan di klinik yang dimiliki oleh aparatur pelayanan. Padahal masyarakat selalu berobat kepada unit pelayanan kesehatan yang diselenggarakan oleh Pemerintah Kota.

\section{Penguatan Unit Kerja Pelayanan}

Beberapa unit pelayanan kesehatan yang terdapat di Kota Pariaman masih menjadi sarana mendapatkan pelayanan kesehatan dibandingkan unit kesehatan yang dikelola oleh pihak non pemerintah. Mengingat kemapuan masyarakat dan penduduk Kota Pariaman, ditemukan hanya sebagian saja penduduk yang ingin dan mau mendapatkan pelayanan dari unit pelayanan kesehatan yang dikelola oleh pihak non pemerintah.

Beberapa masyarakat yang mengunakan pelayanan kesehatan yang dikelola oleh pihak non pemerintah menginginkan pelayanan yang baik dan ramah, dengan memenuhkan keramahan pelayanan yang dilakukan oleh unit pelayanan kesehatan yang dikelola oleh pemerintah, baik itu kemampuan sarana prasarana penunjang dalam pemberian pelayanan dan sikap serta perilaku yang diberikan oleh aparatur yang profesional. Sikap dan perilaku aparatur pada unit pelayanan kesehatan yang masih rendah dalam memberikan pelayanan kepada masyarakat ditambah bentuk pelayanan yang masih bersifat tradisional, masih tercipta dalam pelayanan di daerah mengingat perilaku masyarakat dan penduduk Kota Pariaman yang kuat dan tetap mempertahankan budaya yang sudah turun-temurun.

Pengenalan teknologi untuk meningkatkan daya saing dan pengelolaan birokrasi yang benar dalam pembarian pelayanan kesehatan menjadi perhatian dalam menghadapi persaingan bisnis dari swasta. Agar dapat diperhatikan mulai dari pelaksanaan pemberian pelayanan di awal hingga akhir pemberian pelayanan menjadi faktor kunci untuk dapat bersaing dan memberikan pelayanan yang baik kepada masyarakat.

Iklim organisasi yang baik diperlukan guna menunjang pemberian pelayanan kepada masyarakat. Ditemukan adanya konflik kepentingan antara aparatur penyelenggaran. Lemahnya kemampuan birokrat dalam melakukan penilaian kinerja aparatur di dalam unit pelayanan kesehatan, membuat 
pelayanan kepada masyarakat menjadi tidak maksimal.

\section{SIMPULAN}

Pertama, kinerja aparatur pelayanan di beberapa Puskesmas Kota Pariaman masih perlu ditingkatkan ssikap dalam memberi pelayanan dan wawasan sehingga dalam memberikan pelayanan kepada masyarakat memiliki kompetensi yang memumpuni.

Kedua, membangun iklim organisasi yang kondusif dalam pemberian pelayanan kepada masyarakat mendorong pimpinan unit kesehatan dan para aparatur untuk berkomitmen dalam memberikan pelayanan yang baik kepada masyarakat.

Ketiga, memperkuat organisasi sebagai unit kerja pelayana kesehatan dengan mengubah paradigma aparatur pelaksanan menjadi seorang pelayan, pola pikir, dan pola pandang dalam melakukan pekerjaan yang bersifat pelayanan.

Keempat, membangun komunikasi dalam organisasi yang harmonis, sehingga dalam pelaksanaan pemberian pelayanan tercipta sinergi antartenaga fungsional medis dengan tenaga lainnya untuk memberikan pelayanan kepada masyarakat.

Kelima, penggunaan teknologi untuk membantu pemberian pelayanan perlu menjadi perhatian pemerintah Kota Pariaman melalui, kepastian pelayanan, khususnya dalam penggunaan waktu dan biaya.

Keenam, asistensi evaluasi oleh perangkat pemerintah daerah, khususnya dinas Kesehatan Kota Pariaman secara reguler, sehingga Puskesmas dapat terkontrol dengan baik dan tentunya diharapkan terjadi peningkatan kinerja dan kepuasan masyarakat dalam pemberian pelayanan.

\section{DAFTAR PUSTAKA}

Bono, J.E. \& T.A. Judge (2003). "Self-concordance at work: Toward Understanding The Motivational Effects Of Transformational Leaders", Academy of Management Journal, Vol. 46, No. 5, pp. 554-571.

Dwiyanto, Agus. (2010). Manajemen Pelayanan Publik: Peduli, Inklusif dan Kolaboratif. Gajah Mada University Press, Yogjakarta.

Faustino C. Gomes. (1995) Manajemen Sumber Daya Manusia. Andi Offset, Yogyakarta.

Kotler, Philip. 2005. Manajemen Jasa. PT. Indeks. Jakarta.

Sumber Internet:

http://itjen-depdagri.go.id/index.php?pilih=news\& $\underline{\text { mod=yes\&aksi=lihat\&id=23. }}$. (diakses, 14 Juni 2011) 